\title{
Socioeconomic Determinants of Caste-based Endogamy: A Qualitative Study
}

\author{
Muhammad Rizwan Safdar \\ University of the Punjab, Pakistan \\ Muhammad Akram ${ }^{1}$ \\ Eastern Mennonite University, USA \\ Falak Sher \\ GC University Faisalabad, Pakistan \\ Abid Rehman \\ University of Peshawar, Pakistan
}

\begin{abstract}
The present study is aimed at exploring the socioeconomic determinants and implications of caste-based endogamous marriages in Punjab, the most populous province in Pakistan. The data for this study were collected from a sample of 24 participants (14 males and 10 females), who were married-within-caste, with diverse socioeconomic, educational, and geographic backgrounds. This study found social pressure, protection of family honor, geographic propinquity, and castebased stereotyping as key social factors reinforcing endogamous marriages in the province. Finally, the desire to avoid distribution of family's economic resources like property and land was found to be a leading economic determinant of caste-based endogamy. Further, endogamy hinders economic mobility of lower castes since economic capitals such as land and property are preserved through this marital practice.
\end{abstract}

Keywords: caste, economic dynamics, Endogamy, social factors, marriage system, patriarchy, social factors.

Endogamy is the practice of marrying within one's own social group, tribe, or caste. Endogamy is one of the ancient and indigenous patterns of marriage in the subcontinent (Sofroniou, 2015; Waerzeggers, 2002). Endogamous marriages have been common among ancient aristocracies, ethnic groups, social classes, and religious groups for ages. Caste-based endogamy is prevalent in parts of the sub-continent (Pauls \& Young, 2016). Endogamy is practiced around the world in many forms such as class endogamy (Colantonio et al., 2006), ethnic endogamy (Stevens \& Swicegood, 1987) and caste endogamy (Abraham, 2014). Similarly, racial endogamy (Rosenfeld, 2008), village endogamy (Schwimmer, 2003) and educational endogamy (Rosenfeld, 2008) are prevalent in different parts of the world.

Punjab province in Pakistan comprises $52.9 \%$ of the country's population divided into hundreds of castes (Pakistan Bureau of Statistics, 2017). Caste-based endogamy is common practice among the majority of caste groups in Punjab. Caste-based endogamy is the practice of marriage within a specific caste by rejecting the members of other castes due to perceived caste

\footnotetext{
${ }^{1}$ Correspondent Author E-Mail: akramuhammad1@gmail.com
} 
superiority or inferiority. In this study, caste-based endogamy refers to the customary process of marrying only within one's own caste, clan, or tribe.

Numerous factors influence the decision of endogamous marriages such as socio-cultural pressure (Sofroniou, 2015), fear of social exclusion from the caste group (Bailey \& Peoples, 2013; Beckett \& Kobayashi, 2020; Gil-White, 2005; Sen, 2000), and restrictions on spousal decision by parental influence (Knox \& Schacht, 2012; Zaman, 2011). Marriage within caste is social law in traditional societies like Punjab where people prefer to keep the hereditary lines "pure" by practicing endogamy (Bittles, 2005). Geographical closeness (Snell, 2002), a sense of pride and belonging, caste and family individuality (Imtiaz et al, 2015), maintenance of social ties, and caste bondage strengthening (Ali et al., 2014) are the leading socio-cultural factors of endogamous marriages. The socioeconomic determinants of endogamous marriages are the preservation of property, land, monetary wealth, and other economic resources within a certain social class (Bittles, 2002; Bunescu, 2015; Clark et al., 2014; Saleem et al., 2015). Further it urges communal hierarchy for improved conflict resolution at community levels (Schaefer, 2001; Yee, 2003).

Despite the fact that endogamy causes numerous socioeconomic and health issues, including higher breast cancer among females (Shami et al., 1991), people prefer this marital practice following caste customs, social factors, and economic dimensions. Caste-based endogamous marriages are rooted in Punjab's feudal societal fault lines that follow the old Hindu caste system (Jataayu, 2014). Hence, the typical model of caste-based endogamy in Punjab, Pakistan, is borrowed from the customary Indian culture (Schwimmer, 2003).

Endogamous marriages cause discrimination, prejudice, and ethnocentric sentiments among people living in a society. Caste-based social stratification has serious socioeconomic implications for a society as caste adds social exclusion through regulation of social mobility (Ambedkar, 1916). The notion of superior and inferior castes causes social inequality which hinders equal opportunity. Castes perceived to be superior maintain control over economic and political capital hindering the socioeconomic mobility of individuals from lower castes (Jodhka \& Shah, 2010). Endogamy is practiced to keep the property and wealth within one's caste group, and it is strongly favored amongst landlord and feudalistic castes to preserve their family's property and land (Bittles, 2002).

In the past, studies about different dimensions of caste have been conducted in India (Bittles, 2002; Gupta, 2011; Parmar \& Sengupta, 1994), but caste and caste-based endogamy in Pakistan has largely remained under-studied. There is insignificant literature focused on castebased endogamy in Pakistan (Hussain, 1999; Usman \& Amjad, 2013). Hence, the current study bridges the research gap with an academic supplement of literature. This study aims to explore socioeconomic determinants of caste-based endogamy in order to investigate sociocultural and economic implications of endogamous marriage patterns in Punjab, Pakistan. .

\section{Theoretical Framework}

Filter Theory was used to highlight the process of caste-based endogamy in Punjab, Pakistan. According to Filter Theory, a social structure limits the number of adequate or eligible contenders for a mate because most of the people attempt to marry only those who are like them, known as homogamy (Regan, 2003). If one feels attracted towards another person, Filter Theory proposes that individuals assess their future partner on a rational basis. An individual would be encouraged to examine the family background, socioeconomic status, and physical attractiveness of a potential spouse making the mate selection seems an act of personal choice (Zaman, 2011). Filter Theory posits that individuals filter their potential spouses in two phases as: i) a biological filter, to assess the sexual attractiveness and physical similarity, and ii) a contextual filter, focused 
on the caste, social class, education, religion, ethnicity, and race of the potential spouse. Caste and religion are among the most important factors defining the opinion, attitude, and even the entire behavioral pattern of an individual or family.

Figure 1

Cycle of Filter Theory

\author{
4. Trial filter. \\ needs and \\ expectations via \\ engagement.
}

\section{Psychological \\ filter. attitude and habits and behavioral patterns.}

\section{Decision filter. \\ couple marriage or \\ actors restart to \\ search new \\ partner.

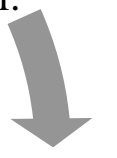

\section{Biological filter. \\ sexual \\ attractiveness and \\ physical similarity.}

\section{Sociocultural}

filter. caste, social class, education, religion, ethnicity and race.

Note: Compiled from the works of Kerckhoff and Davis (1962), Trivers (1972), Murstein (1980), Buss and Schmitt (1993), and Zaman (2011).

Caste and religion similarly serve as primary criteria to choose a partner for marriage (Husain, 1994). People prefer to find partners equivalent to their own class, status, and level of education (Akpan, 2018; Kalmijn, 1998; Mare, 1991; Rosenfeld, 2005). After an assessment of a potential spouse's psychological features like attitude and habits, an individual assesses their complementary needs and the opportunity for the fulfillment of expectations. This phase ensues with a trial filter where spouses determine their potential mate will satisfy the expected needs. Finally, the decision filter decides if the couple gets married or whether they will search for a new partner. In any case, the individual aspirations govern the procedure of mate selection. Filter Theory takes a sociological perspective and assume that people align their individual inclinations with socialization standards before learning about partner inclinations in their sociocultural environment (Trivers, 1972).

The decision of mate selection and marriage remains in the hands of family and baradari (caste) in Punjab. A family prefers marrying their son or daughter within the extended family or caste group. Family elders search for potential spouses and exchange gifts like money and clothes to initiate the discussion with the potential spouse's family. Both families assess the behavior of the potential spouse and their family. Families do not usually permit the potential couple to interact or date during this filtration period. Families evaluate each other's socioeconomic status, property and land, couple's education, employment status, and family's caste positioning. Direct observations and indirect investigations are conducted in this evaluation process. The potential couple gets to know each other through their siblings and relatives, since they are not allowed to 
meet or date themselves. If the evaluation process is successful, family elders make the final decision. Filter Theory compliments the endogamous marriage process because of the way that individuals in a marriage market filter their own future spouse, with the right to terminate the potential relationship. But in Punjab, endogamous marriage customs are held by parents who assess potential spouses for their daughter or son, rather than the marrying individuals assessing one another; this limits choice for the couple themselves (Zaman, 2011).

\section{Research Questions}

This study aims to improve understanding of the socioeconomic determinants of castebased endogamy in Punjab, Pakistan, which later create complex issues at the institutional levels of family, society, and state. The data collection for this study was guided by the following research questions.

1. What are the socioeconomic factors keeping the centuries-old tradition of caste-based endogamy alive in Pakistan?

2. What implications does endogamy have for people belonging to the lower castes?

3. Does endogamy hamper the upward socioeconomic mobility of different castes?

\section{Methods}

Qualitative research design was adopted for this study which facilitated closer interaction with purposively selected research participants. A pretested semi-structured interview guide was used for data collection from participants married endogenously. Semi-structured interviews support the generalizability and relevancy of interviews within larger set of population. The sample size was calculated based on reaching the point of data saturation after determining no new significant information was being attained. Constant and simultaneous comparisons of collected data were made to ensure the saturation level by identifying recurring patterns and themes in the data.

To ensure diversity in the sample, twenty-four in-depth interviews were conducted with males (58\%) and females (42\%) residing in three districts of the Punjab province as Rawalpindi, Faisalabad, and Multan. Eight individuals from each district participated. Interviews were controlled with ability to divert the discussion when needed, rephrase questions, and explain the study context for participants' better understanding. Researchers' bias was addressed by selecting relevant participants per inclusion criteria of being married within their caste group.

The individual interviews were conducted in a private place to ensure the privacy and confidentiality of study participants. Interviews started with brief mutual introductions of participant and researcher, briefing on the study purpose, and ground rules for smooth interview. Each participant consented to voluntary participation before each interview. All of the interviews were audio recorded and assigned a specific code to ensure confidentiality of participants. On average, the time taken for each interview was 45 minutes. After the interview, the researcher compiled the notes, formulated a synopsis of the interview, then transcribed the notes.

The inductive approach of thematic analysis was used for data analysis through NVivo version 10. Interview recordings were transcribed and later translated from Punjabi and Urdu languages to the English language. The English versions of interview files were imported into NVivo for creating nodes, sub-categories, categories, and themes (Table 1). Participant information gathered during the interview included their marital status, age group, caste, and residential location. Content analysis, used in this study, is a widely accepted technique in qualitative research 
methods (Drisko \& Maschi, 2015; Firmin et al., 2018; Zikmund et al., 2013). Textual analysis is a systematic way to analyze the content and identify the relevant themes. This technique is used to analyze the content of body language, audio, and visual data (Harper, 2011; Zikmund et al., 2013).

The age of participants ranged from 20 years to 76 years, and educational level ranged from illiteracy to possession of master's degree. However, most of the participants' education level were below bachelor level. The majority of the participants' monthly household income was between PKR 15,000 to PKR 25,000. In addition to the respect for local norms and values, ethics like privacy, anonymity, and confidentiality of the respondents were ensured in this study (Guillemin \& Gillam, 2004).

\section{Results}

To identify content categories and sub-categories, the transcripts of all the interviews were analyzed using the content analysis method with support of NVivo software version 10 . The transcripts were read twice to assign codes to the interview content which was later summarized to identify sub-categories and categories within the theme of socioeconomic determinants of castebased endogamy. This study found different social and economic factors influencing the marital decisions in Punjab which later resulted in complex issues for the families and for society. The findings of this study are supported by relevant quotations by the study participants.

\section{Table 1}

Theme, Categories, and Sub-Categories illustrating Socioeconomic Determinants of Caste-based Endogamy in Punjab, Pakistan

\begin{tabular}{lll}
\hline Theme & Categories & Sub-categories \\
\hline Socioeconomic & Social determinants of & - Social pressure \\
determinants & caste-based endogamy & - Family honor and prestige \\
and & & - Survival of the caste \\
$\begin{array}{l}\text { consequences } \\
\text { of caste-based } \\
\text { endogamy }\end{array}$ & & - Compromised personal autonomy \\
& & - Uncertainties associated with inter-caste \\
& & marriages \\
& & - Geographic propinquity and easiness \\
\cline { 2 - 3 } & Economic aspects of & - Economics of caste-based endogamous \\
& & marriages \\
& & - Caste-based stereotyping and nepotism \\
& & - Compromised Personal Autonomy \\
& & Limited social capital \\
\hline
\end{tabular}

\section{Social Pressure}

In Punjabi culture, parents and family elders usually decide marriage or mate selection for their children, with a second-fiddle role played by other relatives, peers, and members of their caste group. They make opinions, advice, and suggestions with authority over the potential couple's socioeconomic support. This influences the potential couples to stick with their parents' decision for fear of criticism from peers and relatives if decided otherwise. Female marital nonconformity brings severe results like honor killing and complete withdrawal of familial support and 
association. In certain conditions or circumstances, some parents can accept marrying their sons outside of caste, but that is not a feasible social contract for daughters. A female interviewee said,

Even if a boy's family decides to marry outside the caste, the girl's family would not approve Rishta (marriage proposal). Social pressure from relatives, peers, and neighbors would not let this happen.

Since Punjabi society is traditional in its nature and practice, values-based social structure creates pressure for caste-based endogamous marriages. Marital preferences and choices reflect the likes and dislikes of the potential couple's parents. Furthermore, societal disapproval and caste pride maintenance influence inter-caste marriages in Punjabi society where marriage is considered as a social contract tying the knot between two families rather than two individuals. A female participant shared,

If we will marry a boy from lower castes, he and his male relatives would visit our houses and sit among our daughters and sisters which is not respectable among the upper castes. Jat's (upper caste) boy was married in Julahas (weavers) without the approval of his close relatives. In-laws (of the Jat boy) were beaten up by his cousins and uncles at the time of his father's funeral.

\section{Family Honor and Prestige}

The honor and prestige of Punjabi families is linked to their castes. Inter-caste marriages are perceived as disgraceful for the family and the baradari (caste). Since caste is the primary criterion for social status, parents prefer to arrange marriages of their children within families having equal or higher social status. Punjabi families consider economic conditions as the second priority in the procedure of spousal selection. A male participant said.

Marrying any of our family members outside of our caste will bring shame to our family. Our baradari (caste) and people around us will gossip about the relationship which will disgrace honor of our family elders and forefathers.

In Punjab, honor is usually associated with female family members which makes the endogamous marital practices even more rigid for them. Frameworks of caste-based family honor and its upshot - shame - function to keep in control to regulate and direct a female's freedom of mobility, marriage, and sexuality by male members of a Punjabi family. It is considered against the societal norms and family honor if a female marries outside of the caste. An elder male interviewee said,

Our daughters are our honor, and we (males) are here to protect it. No one from outside our caste can dare request for the Rishta (marriage proposal) of a young girl from our family, no matter how wealthy and educated they are. We, the elders of the family, arrange marriages of our daughters and sons within the baradari (caste) to protect the family honor. 
Education and professional accomplishments or financial wellbeing have least impact on caste-based endogamy structures. It is considered shameful or disruptive by the upper castes like Jats or Rajputs to accept their children's spouse from lower castes like Mochi or Musalli. A rural elder female participant shared,

Marriage is not a game of Gudi Guda (toys), but a serious decision. How can I accept a daughter-in-law in my family who does not belong to our own baradari (caste)? Accepting an in-law from kammi zaat (lower castes) is out of the question. If I do so, it will hurt our family's honor and people will not respect us anymore.

\section{Geographic Propinquity and Easiness}

Endogamy is practiced among Punjabi families to find a spouse within their caste. Most of the villages in Punjab are dominated by a few caste groups urging people to arrange marriages within their own caste and village. People believe that more relatives or members of their caste living within geographic area symbolize greater social power at the community level. The notion of social power urges people to marry a spouse who lives in closer proximity which multiplies their local representation and thus extend their social power. A female participant viewed,

If we, the family, would marry our daughters and sons within our own caste, we will not struggle to search for a suitable life-partner for them because people of our caste are well acquainted with us. We also know the character of all boys and girls of our caste which makes it is easier for us to make a match within caste.

Most of the Punjabi parents do not prefer their children marry into a family living far away. People make marital knots with families living in close proximity in order to share in the joy or grief of their married children, especially the women. Many Punjabi families find it difficult to find a suitable spouse for their children from outside of their caste. Hence, endogamous marriages are a result of the ease of finding a spouse within the same caste group and geographical area, which generates higher trust levels among families. In most of the cases, people identify potential spouses for their children during their teen-age years and within the extended families of a shared caste group. The shared geographic locations make it easier for parents to initiate and finalize this process of mate selection quite early and quickly. One of the male interviewees argued,

The members of our caste are living close by. Hence, we prefer our children's marriage within the extended family and caste. It is difficult to travel for miles on monthly basis to meet the married daughters and their in-laws. It is also not possible for our boys to relinquish routine work and take their wives to their parents if they are residing in another city or district.

\section{Survival of the Caste}

In Punjab, some people believe in endogamous marriages to ensure the survival of their castes. For the preservation of the caste system, different castes require their hereditary features to 
be biologically distinct. Membership of a caste is based on heredity, and casteism places biological and social limitations on inter-caste marriages. Survival of the caste system is important for landowning and for upper castes to ensure social positioning. Since endogamy excludes lower castes and maintains the status quo, people have strong bondage with their castes in Punjab and perceive exogamy as adulteration. A female participant argued,

If we start marrying outside our caste, our caste and family system would totally be damaged. Leaving endogamy behind means that we are saying goodbye to our caste and forgetting our forefathers. The practice of castebased endogamous marriages is centuries old and we do not see any problem with it.

Since upper caste people do not want to lose inherited lands, they are stricter on caste-based endogamy than those of lower castes. With the belief that endogamy brings caste-based solidarity, upper caste families perceive intermarriages as threatening to their structural status quo and the deep-rooted patriarchal system. Their aim is to sustain their social status through the practice of endogamy and through religious justification. A superiority complex pushes landowning castes to practice endogamy, but inferiority complex among lower castes justifies their survival in society. A male participant said,

This system of the universe is created by the Allah (God) Almighty. He has made social hierarchies for better functioning of the universe system. Some are superior while others are inferior. This stratification is also present in the Western world, maybe in other forms but is there too. I am thankful to Allah that I am born in an upper caste. Everyone should be thankful to Allah for whatever they have got.

Moreover, the idea of caste-purity covers the forms of authority and power that are typically used in local settings. People belonging to upper caste groups tend to say in public gatherings that they have strong caste bondage and that inter-marriages are against their caste customs. However, the objective of asserting this idea in public is to preserve their position at the top of the social hierarchy.

\section{Uncertainties associated with Inter-Caste Marriages}

People believe adjusting to the customs, traditions, and values of another caste complicates the success of an inter-caste marriage. It urges the majority's decision of spousal selection according to the needs of family and caste. It is widely believed that inter-caste marriages not only reduce caste identities, but that children born within intermarriage partnerships do not share parental identity. Consequently, those children then face issues of caste recognition, as purity of blood is not maintained. A female participant agreed,

There is no doubt that children born as a result of an inter-caste marriage do not share parental identity. They have a mixture of blood with no specific identity in the society. So, people tend to avoid inter-caste marriages. 
Fear of marriage failure and honor killing are the leading factors of opposition to inter-caste marriages. In Punjabi society, a couple marrying against the vows of their parents and family put themselves at the risk of honor killing for bringing disgrace to the family's honor. Honor killing in both rural and urban areas of Punjab, is associated with a woman eloping to marry. Gender differences exist in honor killing, as honor is associated with female members of the family. A woman's decision to elope and intermarry brings social exclusion, disgrace, and defamation to the whole family. Fear of honor killing influences couples to choose caste-based endogamy. A female shared a story about this.

She was tall and beautiful. She fell in love with a boy who used to work in a textile factory. The boy was also handsome. They eloped and got married against the will of her family. But when the girl's brothers came to know about their Nikah (marital contract), they hunted them down. The boy escaped but girl was killed brutally. No police case was registered against her brothers.

\section{Economics of Caste-Based Endogamous Marriages}

Caste-based endogamy is practiced widely in Punjab to keep economic resources like property and land within the family or caste. Endogamous marriages are believed to help avoid distribution of economic resources for affine exchanges or inheritance of female family members. As per Pakistani law, a married couple is legally required to share property and wealth with their spouse and children. When a woman marries inter-caste, her children belong to her husband's caste. Hence her caste loses the economic resources. As a male interviewee discussed,

\section{Everybody thinks in a different way; it depends on the way one is socialized} and raised. Marriage is an economic decision for most of Punjabi families.

In Punjabi families, the ideal life partner for a son is considered to be the daughter of his father's brother (uncle) or any other female cousin from the father's side of the family. Marriage to a cousin is perceived to protect the property and land of the patriarchal familial lineage. According to Pakistan's inheritance law, a married daughter has the right to inherit paternal land and property. But a women's demand for inheritance is considered against caste traditions and society's patriarchal values. The pressure from family and society forces women to abstain from demanding their share of the property, wealth, or land. Thus, the economic resources remain in the hands of men and fear of economic loss restricts inter-caste marriages. As a male participant opined,

Females do not demand their share in paternal property in our caste traditions. If someone does so, she may lose all her relations. If we start marrying our daughters out of our caste, their in-laws will force them to get their share in the land and property. That will not only result losing our land, but also our daughter.

Amidst the Punjab's dowry custom, the matrimonial ceremony within caste or family decreases or sometimes eliminates the other miscellaneous economic expenses. Family elders in 
village settings decide the marriage arrangements considering different types of economic costs. A female interviewee described this.

When arrange a marriage within extended family or caste, we know how to deal with matrimonial costs. We can easily make a deal with other family about the number of people at the marriage ceremony and control the costs. We can easily talk about exchanges of gifts or dowry. But if you are arranging a marriage outside of our caste, we must go with demands of another family.

Balance of the financial assets of two families is a prerequisite for the marriage process and the reason behind successful marriages in Punjab. Since land resources, family property, and other assets have special importance, it drives the families to arrange the marriage with economic reasoning. Otherwise, they prefer to move on to search for another family with economic status equal to their family. Landowning castes do not consider extending their family ties through marriage with lower castes due to the economic drawbacks like losing their land. Different castes in Punjab have different marriage traditions. The lower castes keep marriage ceremonies simple while landowning castes spend relatively more money on marriages, exchanging gifts, and other arrangements. A female interviewee said,

Landowning castes are generally more generous as compare to the lower castes who are miser and do not spend money on marital arrangements. It brings shame to the family.

Since the caste system is based on the idea of the division of labor, the majority of lower castes inherently engage in lower paying jobs and professions with structural barriers to socioeconomic mobility. In the absence of exogamy or inter-caste marriages, lower castes are devoid of economic mobility.

\section{Caste-based Stereotyping and Nepotism}

The caste system in Punjab has been maintained for centuries through the rule of caste endogamy. Since a caste is an extended and interrelated social pattern, the caste system is rooted in endogamy through caste-based nepotism, stereotyping, and casteism. This social hierarchy prevents the lower castes from challenging the system of supremacy and the privilege of landowning upper castes and their political, social, and economic powers. People from upper and lower castes acknowledge the presence of deep-rooted caste-based nepotism in Punjab. Such nepotism benefits the upper castes while lower castes suffer from stereotyping and discrimination. According to a male interviewee,

This is a fact that people of certain castes are brave while others are cowards. Members of some castes are generous while others are miser. People of Rajput caste have honor and they know how to protect their honor. That is why maintaining purity of blood through endogamy is essential.

The customary functions like endogamous marriages have significant influence upon caste stereotypes. A girl from a lower caste getting married into a Jat family, upper caste, is considered 
the worst conceivable union for the Jat family and the society. One common perception among Punjabi people is that women from lower castes generally do not adjust to the customs and traditions of upper caste families. A female interviewee argued,

Prestigious castes and families should extend their ties with prestigious people. Otherwise, relationships do not work for longer period and family honor is usually lost.

People of upper castes believe that lower castes like mussallis and churhas (lower castes) are polluted and will pollute even their pots if they share food with them. Thus, they believe marrying someone from the lower castes will adulterate the purity of upper castes. The perceptions of lower caste people are influenced by misinterpreted religious justifications for caste-based discrimination, such as saying that people are born in a lower caste family by God's will. As a female interviewee discussed,

I was born in mussaali baradari (lower caste) and I am a house maid. I serve five houses in posh areas of the city on a daily basis. The owners are mostly government servants while females are housewives. All the houses have allocated separate pots like glasses and mugs for me to eat and drink. Nevertheless, I never mind this behavior of house owners as this is happening with us (mussallis) since centuries.

\section{Compromised Personal Autonomy}

Parents and relatives encourage and even force their young family members to marry within extended families or caste groups. This practice limits individual autonomy and result in negative consequences for the married couple and their families. Previous literature has termed such marriages as "forced marriage" where children have a limited role of spousal selection. Most of the Punjabi children, especially girls, think spousal selection is the right of parents which they must accept. Some people believe those of young age are not mature enough to make critical decisions regarding marriage. A female interviewee stated,

If given chance, children will not make rational decisions by thinking emotionally which will result wrong marital. Further, children may not stick for long to their decision which will result in divorce. Hence, family system will be affected badly.

Parents' belief in endogamy compromises their children's personal autonomy for social wellbeing. Punjabi parents often justify forced marriages, domestic violence, and endogamous marriages. A male interviewee argued.

Few people relate domestic violence to cousin marriages and endogamy, but it can also be found in societies where intermarriages are not common. Love marriages also have negative consequences. You know about the divorce rate in Western societies where young children have liberty to marry whoever they want. 


\section{Limited Social Capital}

Caste has created various endogamous partnerships, restricting social melding. People from upper or landowning castes usually have strong social networks due to their socioeconomic status, but this is not the case with people from lower castes. Strong social capital can smooth the socioeconomic journey of those in a landowning caste while making it difficult for people from lower castes. As the caste system in Punjab limits interbreeding, each caste produces its own social capital to compete with other castes. Landowning castes preserve and strengthen their social capital through endogamous marriages while lower caste people suffer marginalization and deprivation. People from lower castes believe in the fragility of their social relations and end up in the same vicious circle due to endogamous marriage patterns. A male interviewee said:

Since different castes do not intermarry and have maintained separate identities, their social capital is not enhanced, especially of kammi castes that are at the mercy of landowning castes. The social capital of almost all castes doesn't cross the caste boundaries, which means that the mobility of the caste groups is also hampered.

In conclusion, caste endogamy preserves a clear divide among different castes in Punjabi society. Some castes have strong social relations because they inherited better economic conditions, while others have limited social relations and are subjected to discrimination. Endogamy is practiced to enhance and sustain social capital by promoting cooperation among upper or landowning castes. Different castes promote their caste in businesses or job markets. Inter-caste marriages could help lower caste members to increase their social and economic capital. A male interviewee said,

If people start to marry without considering caste of potential spouse or their family, there is no doubt for increase in social capital of people. The lower caste people will benefit more from inter-caste marriages, but I am afraid inter-caste marriages will not be acceptable for upper castes anyway.

\section{Discussion and Conclusion}

The choice of mate selection in Punjab has always been in the hands of family elders, mostly parents, as they choose to marry their children within their own caste, family, or social class. They practice endogamy believing in stronger marital alliances for closer caste ties and cohesion. This hampers socioeconomic mobility of the lower castes and permits unequal retention of resources within the upper castes. Caste system in Punjab prevents the socioeconomic mobility of lower castes through social sanctions and religious and political authorization. Since the people in castebased societies have strong perceptions about the failure of inter-caste marriages, young couples remain afraid of losing social and parental support and continue living unsuccessful lives (Bhusal, 2013). In Punjab, inter-caste marriages are considered socially stigmatizing with the least socioeconomic support from parents. Endogamous marriage patterns maintain social barriers in the society (Bailey \& Peoples, 2013).

Caste-based endogamy maintains exclusivity in two ways. First, it reduces the interactions and contacts among people of different castes. Second, it restrains relationships between different 
caste groups which creates social stratification. Gil White (2005) indicated endogamy enforcement by parents within caste or ethnic group maintains the social barriers. This results in a group's social isolation from cultural developments and integration into other communities, even if those communities are living side by side.

The study found that the decision of marriage and mate selection is determined by numerous factors like social pressure of family, caste group, and society. This social pressure associates the concept of family honor with marriage and geographic propinquity additionally paves the way to caste-based endogamy (Usman \& Amjad, 2013). Parents in traditional families do not prefer to marry their children in far-off places.

People avoid intermarriages to prevent challenges from the caste system, like fear of marriage failure (Srinivasan \& James, 2015). The practice of endogamy also preserves economic resources like property and land within the family. The concepts of caste purity and pride, social pressure, and family honor were among major factors behind the caste-based endogamy in Punjab. Couples married without the consent of parents face opposition from peers and relatives with risks of economic boycott (Grover, 2017).

Cultural and family values put individuals in a situation to conform to endogamy; parental authority sustains endogamous marriages and the subsequent caste system (De Neve, 2016; Verma \& Sukhramani, 2018). Socioeconomic insecurities associated with intermarriages and fear of intermarriage failure push people to practice strict to caste-based endogamy in both urban and rural areas of Punjab (Bhale, 2013). Moreover, people arrange endogamous marriages to preserve family property and land. Parents become afraid of losing inherited economic resources if their children marry outside of their own extended family or caste (Narzary \& Ladusingh, 2019). Since children's education depends upon the economic resources, endogamy influences the social mobility by restricting the educational opportunities for children born in lower castes (Awoyemi, 2014).

Previous scholarship has examined different censuses, marriage licenses, and surveys to distinguish marital patterns in different societies. However, this study brings forth an enriched qualitative account with in-depth empirical insight into caste-based endogamy. In patriarchal societies like Punjab, Pakistan, the probable effects of endogamous marriages are still underexplored, leaving significant space for future research.

\section{Funding Details}

The authors neither got any funding to accomplish this research nor claimed the costs from any agency to publish in open access.

\section{Disclosure Statement}

The authors declare no conflict of interest.

\section{End Notes}

Baradari: It is a form of caste (or clan) system operating amongst the Punjabis and the people of other ethnicities in Pakistan.

Kammi: A member of the low caste, such as Kumhar, Nai etc in Punjabi culture.

Mussalli: A member of the lower caste in Punjab. Mussallis are called Dalits in India.

Nikah: In Islam, it refers to the legal contract for marriage between a man and a woman.

Rishta: It refers to the marriage proposal/relational between two families and individuals. 
Zaat: Caste is known as zat or zaat in many parts of Punjab.

\section{References}

Abraham, J. (2014). Contingent caste endogamy and patriarchy. Economic and Political Weekly, 49(2), 56-65.

Akpan, L. (2018). The Political undertone in the development of nomadic education in Africa: Lessons from Nigeria. American Journal of Qualitative Research, 2(1), 1-21. https://doi.org/10.29333/ajqr/5791

Ali, Q. U. A., Chaudhry, A. G., Ahmed, A., \& Farooq, H. (2014). Psychological ailments and schizophrenia: An anthropological description of endogamous marriage patterns and family institution. European Academic Research, 2(7), 8775-8786.

Ambedkar, B. R. (1916). Castes in India: Their mechanism, genesis, and development. The Columbia University.

Awoyemi, J. A. (2014). Pre-marital counselling in a multicultural society. Lulu.com.

Bailey, G., \& Peoples, J. (2013). Essentials of cultural anthropology. Cengage Learning.

Beckett, G. H., \& Kobayashi, M. (2020). A Meta-study of an Ethnographic Research in a Multicultural and Multilingual Community: Negotiations, Resources, and Dilemmas. American Journal of Qualitative Research, 4(1), 85-106. https://doi.org/10.29333/ajqr/8267

Bhale, A. G. (2013). Perspective of educated youths towards the inter-caste marriage. IJAAR, I(1), $18-28$.

Bhusal, R. (2013). Inter-caste marriage: Social support and family care in contemporary rural Nepal. Retrieved January 18, 2018, from http://www.kuasu.cpier.kyoto-u.ac.jp/wpcontent/uploads/2015/12/Rajesh-Bhusal1512.pdf

Bittles, A. H. (2002). Endogamy, consanguinity, and community genetics. Journal of Genetics, 81(3), 91-98.

Bittles, A. H. (2005). Endogamy, consanguinity, and community disease profiles. Public Health Genomics, 8(1), 17-20. https://doi.org/10.1159/000083332

Bunescu, I. (2015). Roma in Europe: The politics of collective identity formation. Routledge.

Buss, D. M. B., \& Schmitt D. P. (1993). Sexual strategies theory: A contextual evolutionary analysis of human mating. Psychological Review, 100(2), 204-232.

Clark, G., Cummins, N., Hao, Y., \& Vidal, D. D. (2014). The Son also rises: Surnames and the history of social mobility. Princeton University Press.

Colantonio, S. E., Fuster, V., \& Marcellino, A. J. (2006). Class endogamy, inbreeding and migration during the Argentinean colonial period: Analysis based on individuals of European ancestry. Anthropologischer Anzeiger, 311-319.

De Neve, G. (2016). The economies of love: Love marriage, kin support, and aspiration in a South Indian garment city. Modern Asian Studies, 50(4), 1220-1249.

Drisko, J. W., \& Maschi, T. (2015). Content analysis. Oxford University Press.

Firmin, M. W., DeWitt, K., Elllis, H. M., Smith, L. A., \& Tiffan, N. (2018). A Qualitative Study of the Motivations and Affiliation Dynamics Involved with a Firefighting Career. American Journal of Qualitative Research, 2(2), 60-73.

Gil-White, F. J. (2005). Is ethnocentrism adaptive? An ethnographic analysis. University of Pennsylvania.

Grover, S. (2017). Marriage, love, caste, and kinship support: Lived experiences of the urban poor in India. Taylor \& Francis. 
Guillemin, M., \& Gillam, L. (2004). Ethics, reflexivity, and "ethically important moments" in research. Qualitative Inquiry, 10(2), 261-280.

Gupta, V. (2011). Genomic efficiency of endogamy in India. International Journal of Human Genetics, 11(3), 199-201. https://doi.org/10.1080/09723757.2011.11886143

Harper, D. (2011). Choosing a qualitative research method. In D. J. Harper \& A. R. Harper (Eds.), Qualitative Research Methods in Mental Health and Psychotherapy (pp. 83-98). Wiley Blackwell.

Husain, A. (1994). Human Mating Behavior. Northern Book Centre.

Hussain, R. (1999). Community perceptions of reasons for preference for consanguineous marriages in Pakistan. Journal of Biosocial Science, 31(4), 449-461.

Imtiaz, S., Ilyas, Z., Chaudhry, A. G., \& Hadi, S. A. (2015). Social change, modernity, and endogamous marriages: Anthropological analysis. Pakistan Association of Anthropology, Islamabad, 27, 695-697.

Jataayu, (2014). Caste is hardly an impediment for 'homecoming Hindus'. Retrieved June 20, 2018, from https://swarajyamag.com/culture/caste-is-hardly-an-impediment-for-homecominghindus

Jodhka, S., \& Shah, G. (2010). Comparative contexts of discrimination: Caste and untouchability in South Asia. Economic and Political Weekly, 45(48), 99-106.

Kalmijn, M. (1998). Intermarriage and endogamy: Causes, patterns, trends. Annual Review of Sociology, 24, 395-42.

Kerckhoff, A. C., \& Davis, K. E. (1962). Value consensus and need complementarity in mate selection. American Sociological Review, 27(3), 295-303.

Knox, D., \& Schacht, C. (2012). Choices in relationships: An introduction to marriage and the family. Nelson Education.

Mare, R. D. (1991). Five decades of educational assortative mating. American Sociological Review, $56(1), 15-32$.

Murstein, B. I. (1980). Mate selection in 1970s. Journal of Marriage \& the Family, 42(4), $777-$ 792.

Narzary, P. K., \& Ladusingh, L. (2019). Discovering the Saga of inter-caste marriage in India. Journal of Asian \& African Studies, 54(4), 588-599.

Pakistan Bureau of Statistics. (2017). Population census 2017. Retrieved December 20, 2018, from https://web.archive.org/web/20171015113737/http://www.pbscensus.gov.pk/

Parmar, D., \& Sengupta, L. K. (1994). Marital distance and village endogamy in Bhilala and Barela tribes of West Nimar in Central India. Journal of Human Ecology, 5(2), 127-130.

Pauls, P. E., \& Young, G. (2016). Endogamy. Encyclopaedia Britannica Inc. Retrieved April 20, 2017, from https://www.britannica.com/topic/endogamy

Regan, P. C. (2003). The Mating Game: A Primer on Love, Sex, and Marriage. Sage Publications.

Rosenfeld, M. J. (2005). A critique of Exchange Theory in mate selection. American Journal of Sociology, 110(5), 1284-1325. https://doi.org/10.1086/428441

Rosenfeld, M. J. (2008). Racial, educational, and religious endogamy in the United States: A comparative historical perspective. Social Forces, 87(1), 1-31. https://doi.org/10.1353/sof.0.0077

Saleem, H., Chaudhry, A. G., \& Riaz, M. (2015). Endogamy and marital alliances: Anthropology of indigenous marriage patterns. Pakistan Association of Anthropology, Islamabad, 27(2), 1603-1605.

Schaefer, R. T. (2001). Sociology. McGraw- Hill. 
Schwimmer, B. (2003). Lineage endogamy. Department of Anthropology at University of Manitoba. Retrieved November 6, 2017, from https://www.umanitoba.ca/faculties/arts/anthropology/tutor/marriage/lineage_endogamy.h tml

Sen, A. (2000). Social exclusion: Concept, application, and scrutiny. Office of Environment and Social Development, Asian Development Bank.

Shami, S. A., Qaisar, R., \& Bittles, A. H. (1991). Consanguinity and adult morbidity in Pakistan. The Lancet, 338(8772), 954-955.

Snell, K. D. (2002). English rural societies and geographical marital endogamy, 1700-1837. The Economic history review, 55(2), 262-298.

Sofroniou, A. (2015). Therapeutic Psychology. Lulu.com.

Srinivasan, K., \& James, K. S. (2015). The golden cage: Stability of the institution of marriage in India. Economic and Political Weekly, 50(13), 38-45.

Stevens, G., \& Swicegood, G. (1987). The linguistic context of ethnic endogamy. American Sociological Review, 52(1), 73-82.

Trivers, R. (1972). Parental investment and sexual selection. In B. Campbell (Ed.), Sexual selection and the descent of man, 1871-1971 (pp. 136-179). Aldine.

Usman, A., \& Amjad, A. (2013). Caste based endogamy in a Punjabi village of Pakistan. South Asian Studies, 28(2), 341.

Verma, S., \& Sukhramani, N. (2018). Interfaith marriages and negotiated spaces. Society \& Culture in South Asia, 4(1), 16-43.

Waerzeggers, C. (2002). Endogamy in Mesopotamia in the first millennium BC, In mining the archives festschrift for Christopher Walker on the occasion of his 60th birthday. ISLET, 1, 319-342. http://hdl.handle.net/1854/LU-158894

Yee, G. A. (2003). Poor banished children of eve: Woman as evil in the Hebrew bible. Fortress Press.

Zaman, M. (2011). Exchange marriages in South Punjab, Pakistan: A sociological analysis of kinship structure, agency, and symbolic culture. Peter Lang.

Zikmund, W. G., Babin, B. J., \& Griffin, M. (2013). Business research methods (9th ed.). South Western.

\section{Notes on Contributors}

Muhammad Rizwan Safdar is Assistant Professor of Sociology at the Institute of Social and Cultural Studies, University of the Punjab, Pakistan. His research interests are culture, media sociology and politics. He holds Ph.D. Sociology from GC University Faisalabad, Pakistan.

Muhammad Akram is graduate of Eastern Mennonite University, USA, and Atlas Corps alumnus of Emerging Global Leaders Initiative by the U.S. Department of State. He consults on research and evaluation in fragile contexts and writes on community justice and peacebuilding.

Falak Sher earned PhD Sociology and is Director of the Institute of Arts and Sciences at Government College University Faisalabad, Pakistan. He specializes in community psychology.

Abid Rehman is a senior research, monitoring, and evaluation expert on the fragility and destabilization. He is political sciences graduate from the University of Peshawar, Pakistan. 